\title{
REVISED Revisiting early-stage COVID-19 strategy options
}

\section{[version 3; peer review: 2 approved]}

\author{
Philip Machanick (10)
}

Computer Science, Rhodes University, Makhanda, Eastern Cape, 6140, South Africa

V3 First published: 04 May 2020, 9:327

https://doi.org/10.12688/f1000research.23524.1

Second version: 27 Aug 2020, 9:327

https://doi.org/10.12688/f1000research.23524.2

Latest published: 23 Apr 2021, 9:327

https://doi.org/10.12688/f1000research.23524.3

\section{Abstract}

Background: Early-stage interventions in a potential pandemic are important to understand as they can make the difference between runaway exponential growth that is hard to turn back and stopping the spread before it gets that far. COVID19 is an interesting case study because there have been very different outcomes in different localities. These variations are best studied after the fact if precision is the goal; while a pandemic is still unfolding less precise analysis is of value in attempting to guide localities to learn lessons of those that preceded them.

Methods: I examine two factors that could differentiate strategy: asymptomatic spread and the risks of basing strategy on untested claims, such as potential protective value of the Bacillus CalmetteGuerin (BCG) tuberculosis vaccine.

Results: Differences in disease progression as well as the possibility of alternative strategies to prevent COVID-19 from entering the runaway phase or damping it down later can be elucidated by a study of asymptomatic infection. An early study to demonstrate not only what fraction are asymptomatic but how contagious they are would have informed policy on nonpharmaceutical interventions but could still be of value to understand containment during vaccine roll out.

Conclusions: When a COVID-19 outbreak is at a level that makes accurate trace-and test possible, investigation of asymptomatic transmission is viable and should be attempted to enhance understanding of spread and variability in the disease as well as policy options for slowing the spread. Understanding mild cases could shed light on the disease in the longer term, including whether vaccines prevent contagiousness.

\section{Keywords}

COVID-19, early-stage pandemic intervention, asymptomatic transmission

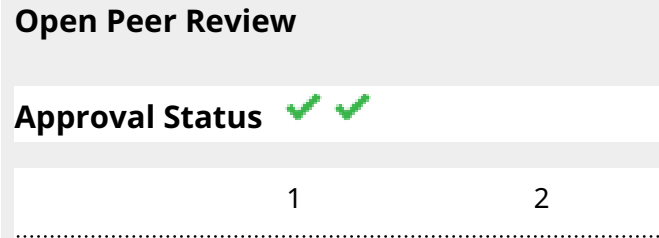

version 3

(revision)

23 Apr 2021

version 2

(update)

27 Aug 2020

$\begin{array}{cc} & \\ \text { view } & \text { view } \\ ? & ? \\ \text { view } & \text { view }\end{array}$

version 1

04 May 2020

1. Siddharth Sridhar ID, University of Hong

Kong, Hong Kong, Hong Kong

2. Agata Mikolajczyk Wroclaw University

of Environmental and Life Sciences, Wroclaw,

Poland

Any reports and responses or comments on the article can be found at the end of the article. 


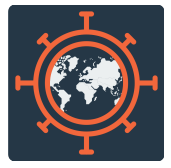

This article is included in the Emerging Diseases

and Outbreaks gateway.

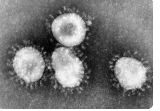

This article is included in the Coronavirus

collection.

Corresponding author: Philip Machanick (p.machanick@ru.ac.za)

Author roles: Machanick P: Conceptualization, Formal Analysis, Investigation, Writing - Original Draft Preparation, Writing - Review \& Editing

Competing interests: No competing interests were disclosed.

Grant information: The author(s) declared that no grants were involved in supporting this work.

Copyright: $\odot 2021$ Machanick P. This is an open access article distributed under the terms of the Creative Commons Attribution License, which permits unrestricted use, distribution, and reproduction in any medium, provided the original work is properly cited.

How to cite this article: Machanick P. Revisiting early-stage COVID-19 strategy options [version 3; peer review: 2 approved] F1000Research 2021, 9:327 https://doi.org/10.12688/f1000research.23524.3

First published: 04 May 2020, 9:327 https://doi.org/10.12688/f1000research.23524.1 


\section{REVISED Amendments from Version 2}

I added New Zealand and Taiwan to the case studies, clarified the role of $R_{0}$ and $R_{\mathrm{t}^{\prime}}$ clarified points raised by the reviewers, and updated my review of the literature. I removed BCG vaccination as a solution, though pointing to the broader principle of avoiding conclusions based purely on correlation and made masking less of a focus. Specific updates to the literature include reflecting lower levels of asymptomatic infection than earlier reports, estimates of the reduced but nonzero reproduction rate of asymptomatic infection, advances in understanding the immune response in asymptomatic infection. I added discussion of how vaccinations could result in a similar pattern to asymptomatic infection of reduced transmission.

Any further responses from the reviewers can be found at the end of the article

\section{Introduction}

When I first submitted this paper in May 2020, I wrote with some urgency because I believed the issue of asymptomatic transmission of COVID-19 was not receiving the attention it deserved, and updated the paper before any reviews were in. All the versions of the paper, read in conjunction of the reviews, form a living review, showing progress in my understanding of the issue and progress in research into asymptomatic transmission.

As the COVID-19 pandemic has spread, its outcomes have differed by locality. In some, it has been contained quickly. In others, the rapid growth has slowed but not stopped. In many, the rapid growth has driven health systems to the point of collapse. New York state is the epicenter of the United States epidemic. What adds urgency to the search for alternative containment strategies is the fact that mortality rate (deaths as a fraction of population) in New York state on 22 April 2020 surpassed 1000 per million. If scaled to the entire country, this would be over 300,000 deaths $^{1}$. At time of writing the second version of this paper, US deaths were at almost 180,000 and that count exceeded 500,000 by the third version, illustrating that there is still work to be done at containment.

Since the pandemic is still playing out it is useful to reflect on the positive and negative outcomes and to try to map a way ahead for localities where it has not gone past the stage where it can easily be contained. Given that no known remedy exists for the disease, and that it is spreading too fast to rely on a vaccine to avoid major health or economic problems, non-pharmaceutical interventions (NPI) are the most critical thing to get right. Now that the pandemic has progressed beyond its initial stages, understanding asymptomatic transmission remains important as the question of universal mask wearing remains controversial $^{1}$ with inadequate testing of informal masks nonetheless at least justifying their use in terms of the precautionary principle ${ }^{2}$. One study shows that viral shedding starts 2 days or more before symptoms show and that infectiousness

${ }^{1}$ The data source for cases and fatalities, unless otherwise stated, is the Worldometers web site. peaks 1-2 days prior to symptoms and presymptomatic transmission is $37 \%$ to $48 \%$ and that this figure can be as high as $62 \%$ without adequate case finding. There are no definitive studies of asymptomatic transmission, despite evidence that it is real ${ }^{3}$.

While understanding asymptomatic transmission alone does not fill the gap in investigating the efficacy of informal masks, it strengthens the case for applying the precautionary principle pending such a study. Studying informal masks is inherently difficult as there is so much variability, which is why I propose an initial focus on asymptomatic infection. Asymptomatic infection can also assist with understanding the highly variable progression of the disease. At a later stage of the pandemic, understanding transmission from milder cases could also be of value in understanding whether vaccines prevent further transmission.

A number of NPIs have been tried from social distancing to complete lockdowns. The consequence of acting too slowly is the risk of crashing a health system, which has hit some of the best in the world (Italy for example has historically been near the top of the World Health Organization's ranking ${ }^{4}$; and the epicentre of the COVID-19 outbreak is in the north ${ }^{5}$, which has Italy's strongest health resources ${ }^{6}$. Though the pandemic at time of writing is still developing, it is worth reviewing options for countries able to avoid runaway exponential growth.

By way of example, I looked at options for South Africa, which embarked on a 21-day lock down ${ }^{7}$ that started at about the time when 1,000 cases were reported (midnight, 26 March 2020; subsequently extended by another two weeks to 30 April), in the first version of this paper. At this much later stage of progress of the pandemic, countries where cases are declining have the same opportunity to use spare testing capacity for a study I propose in this paper.

I examine case studies in other localities encompassing the variability in outcomes and assess likely contributing factors to this variance. Given the shortness of time to make decisions, I do not attempt to develop a rigorous model but rely on extracting meaning from these case studies.

In my opinion, ignoring asymptomatic spread is a major error; a relatively simple experiment in a country like South Africa at the early stage of spread (or now at a later stage as outlined above) could validate this opinion. If proved correct, many lives could be saved. If proved incorrect, the cost is low relative to the benefit. I therefore urge that the experiment be carried out as a matter of urgency.

It is natural at an early stage of a rapidly-expanding pandemic to focus on the most serious cases as these are the ones where interventions make the biggest difference. Now that there is more time to assess evidence, there is also a case to do detailed studies of less serious cases to understand better what predicts progression to the worst effects. Identifying asymptomatic cases in particular could aid with this as they represent the extreme of the mild form of the disease. 
In the remainder of the paper, I describe significant unknowns, work through cases studies and examine other factors, leading to the conclusion that a study of asymptomatic spread was the most urgent gap in early knowledge that should have been addressed to assess options for containment containment - and could still be of use at later stages of the pandemic. I propose a strategy for identifying and investigating asymptomatic cases.

\section{Significant unknowns}

Because testing started under pressure, standards are not consistent $^{8}$. That means statistics like case fatality rate are problematic to compare across localities.

Another big unknown is the true number of infections since many that were not serious enough to require hospitalization may have resolved without being counted where testing was inadequate; if the asymptomatic fraction is as high as claimed in some instances, that also skews the case fatality rate high.

All of these factors also result in difficulty in establishing an accurate value for the basic reproduction rate $R_{0}$, the initial mean number of infections per infected case. The value of $R_{0}$ matters for computing the herd immunity level, widely reported in the mass media as $60 \%$ of the population, the number used to justify the initial British response of allowing it to run through the population'. As infections spread, the effective reproduction number at time $t, R_{t}$, will decline below 1 , the herd immunity threshold ${ }^{10}$. NPIs artificially force $R_{t}$ to drop, faking the effect of a less contagious disease. However, if NPIs are relaxed before herd immunity is reached, another round of rapid increase can ensue as $R_{t}$ again rises above 1 . It is for this reason that estimation of $R_{t}$ is useful ${ }^{11}$.

Herd immunity occurs when the fraction of the population immunised (either by vaccination or by acquiring immunity post-infection) exceeds the threshold $P_{\text {herd }}$ in Equation 1,

$$
P_{h e r d}=\frac{1}{E}\left(1-\frac{1}{R_{0}}\right)
$$

where $P_{\text {herd }}$ is the fraction of the population at which infections peak $\left(R_{t}=1\right)$ and $E$ is the effectiveness of immunisation. If immunisation is $100 \%$ effective $(E=1)$, Equation 1 becomes $^{12}$ :

$$
P_{h e r d}=1-\frac{1}{R_{0}}
$$

Figure 1 illustrates how $P_{\text {herd }}$ varies with $R_{0}$ (assuming $E=1$; in the absence of a vaccine, this means that any recovered cases cannot be reinfected). For seasonal influenza, if $R_{0}=1.3$, the herd immunity threshold is $23 \%$. For $R_{0}=2.5$, the herd immunity threshold is $60 \%$. However, if the true COVID-19 $R_{0}$ value is significantly higher, so is the the herd immunity threshold. For example, if $R_{0}=4, P_{\text {herd }}$ is $75 \%$.

Even for influenza, $R_{0}$ can vary widely depending on the strain. For the H1N1 strain, $R_{0}$ was estimated at 1.4-1.6; for the 1918 flu, the estimated $R_{0}$ range is $1.4-2.8$ and even seasonal flu has a wide $R_{0}$ range of $0.9-2.1^{13}$.

One study reports COVID-19 $R_{0}$ values varying from 1.4 to $3.8^{14}$. Another narrows the range to 2.24 to $3.58^{15}$.

A model with $R_{0}=2.68$ yields a doubling time of 6.4 days ${ }^{16}$. (which would hold good until the fraction susceptible dropped enough to reduce $R_{t}$, unless NPIs artificially reduced $R_{t}-$ it is this phase of expontial growth that puts health systems under pressure). The doubling time was far shorter than this during peak growth in places where it was not under control. In the United States, for example, doubling time was less than 3 days 1-24 March 2020 (see Figure 2, based on the rule-of$70^{17}$ ). That rapidity of growth suggests that $R_{0}$ is on the high rather than low side of published estimates, but the low level of testing in the USA at early stages of the pandemic make it difficult to derive robust measures.

With so much uncertainty, relying on herd immunity is folly, as was discovered in the $\mathrm{UK}^{9}$.

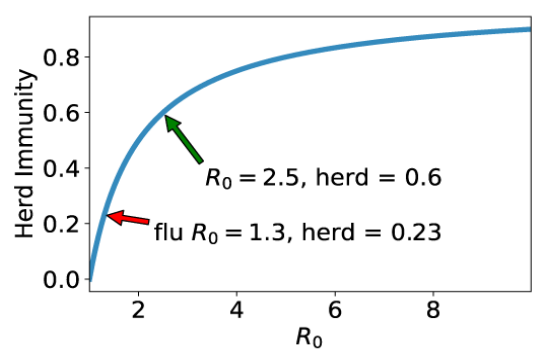

Figure 1. Herd immunity varying with basic reproduction rate $\boldsymbol{R}_{0}$. If $R_{0}$ for COVID-19 is 2.5, herd immunity occurs after $60 \%$ of the population is infected (green arrow). The mean $R_{0}$ value for seasonal influenza results in herd immunity at about $23 \%$ of the population (red arrow).

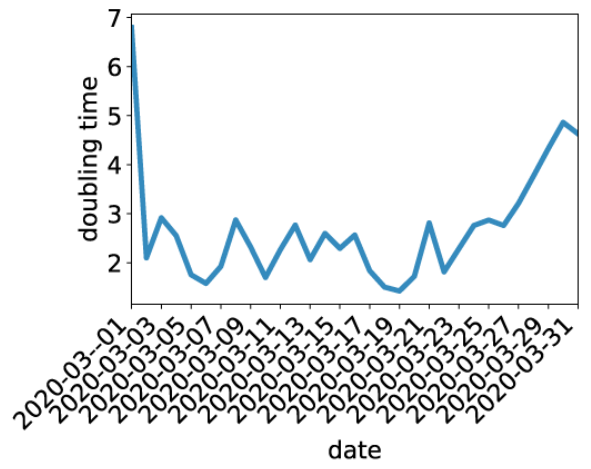

Figure 2. Doubling time in the US: 1-31 March 2020. For much of the month, doubling time is $2-3$ days, implying that $R_{t}$ is not varying significantly. 
Broadly speaking, countries with a tradition of personal liberty and rejecting authority have found it hard to adapt to NPIs like social distancing ${ }^{18}$. Informal settlements and other high-density dwellings of the poor also make social distancing hard ${ }^{19}$. For this reason, it is important to explore all alternatives including those that were missed in early stages so that other countries that are being hit later can learn the right lessons.

\section{Methods}

I use Python 3.7.4 within the Jupyter Notebook environment version 6.0.3 to do anyalysis. All the code used is archived on GitHub $^{20}$ and is labelled as version 1.1.1.

Data is from the Worldometers web site and papers cited; data used in analysis is embedded in the GitHub archive ${ }^{20}$. A snapshot of the Worldometers site containing the data used is archived at Webarchive (updated in Webarchive for Version 2 of the paper).

Herd immunity is calculated based on the standard formula assuming exponential growth using Equation 2.

I calculate doubling time for March 2020 using the rule-of-70, which assumes exponential growth and is accurate under that assumption:

$$
t_{\text {double }}=\frac{70}{r_{\text {growth }}}
$$

Where the growth rate is expressed as a fraction of 100. For example, if the growth rate $r_{\text {growth }}=40 \%$ then:

$$
t_{\text {double }}=\frac{70}{40}=1.75
$$

The number 70 derives from the fact that $0.7 \approx \ln (2)^{17}$.

\section{Case studies}

I consider three cases: instances where the disease has run its course, examples where containment has slowed the growth to the point of being manageable and finally examples where growth has severely stressed health systems.

These examples are not meant to be exhaustive but provide archetypes of different types of outcome.

\section{Run to completion}

I use two types of localities as examples of where the disease has effectively run to completion: cruise liners and a village in Italy, Vo'Euganeo. While localities like Taiwan and New Zealand may not have run to completion, they are useful to include as a retrospective on a potential elimination strategy.

I take Diamond Princess, a widely cited case, as representative of the first kind.

\section{Cruise liner}

Diamond Princess is one of the most documented examples. Of the 3,711 passengers and crew on board, 634 tested positive out of the 3,063 tested and 328 were asymptomatic ${ }^{21}$ - meaning that over $50 \%$ were asymptomatic.

It may seem startling how few tested positive. Given the constrained environment of a cruise liner, a higher rate of social mixing would be expected than in normal living conditions. Once it was known that there was an infectious condition on board, effective NPIs could explain this and result in reducing $R_{t}$.

However the major figure to take way from this is the fact that over half were asymptomatic.

\section{Italian village}

For the Italian village, the number of cases that tested positive but were asymptomatic were in the range of $50-75 \% 22$. More recent meta-anslyses have suggested that the true asymptomatic fraction may be as low as $15-20 \%{ }^{23-25}$. Classifying a case as asymptomatic may arise from not following up, since pre-symptomatic infectiousness can start several days before symptoms show ${ }^{26}$.

What is particularly noteworthy is that $100 \%$ of the population was tested so no asymptomatic cases were missed. This completeness of coverage does not guarantee that a similar result would occur in a different population but at least provides a clear data point. All positive cases were isolated. The number who were ill fell from 88 to 7 in 10 days.

By contrast with this strategy, on 25 February 2020, the strategy for the rest of Italy changed from broad testing of all contacts to a focus on only testing those who had clear symptoms and required hospitalization ${ }^{27}$. This decision was taken when the country had less than 100 cases.

It is a puzzle why it should be more important to test cases who must be hospitalized anyway rather than find those in the community who may be contagious.

I quote the advice of Italian immunologist Prof Romagnani (via Google Translate):

It is therefore absolutely essential to extend the swabs to the majority of the population, in particular to risk categories (i.e. exposed to multiple contacts), and therefore isolate the virus positive subjects and their contacts, even if asymptomatic, as early as possible. In particular, it is absolutely necessary to swab all those who have a high probability of transmitting the virus, especially if they live in closed communities with multiple and close contacts. Finally, it is very important that all those at risk wear masks, not so much to protect themselves from infection, but rather to protect others from themselves, even when they do not show symptoms.

${ }^{2}$ The wide range is not explained - possibly defining asymptomatic is imprecise. 
Even if we take the lower figure of $50 \%$ of the Vo'Euganeo being asymptomatic, ignoring this factor in early testing strategies was a major error. However, in a larger population it is not practical to test everyone and not necessarily useful as a person tested negative could subsequently be infected. Instead, treating everyone exposed to a known case as infected until proved otherwise would catch a significant fraction of the asymptomatic cases.

\section{Elimination}

Taiwan and New Zealand both had robust public health responses that effectively stopped the pandemic. In both examples, contact tracing and testing were followed by isolation of all close contacts and quarantining of positive cases. The main difference between the two is that Taiwan was ready at the outset, whereas New Zealand had to use lockdowns to bring infections under control. The key requirement for an elimination strategy is treating all close contacts as potentially infected, underlining the role of asymptomatic transmission ${ }^{28}$.

\section{Slower growth}

Several countries have managed to contain exponential growth after a major outbreak. Two examples are China and South Korea.

Since China had the first outbreak, they did not act fast enough and had to close down a major part of their economy. Much of Hubei province was effectively placed under quarantine on 23 January 2020, using methods such as tracking social media to enforce it. Since China is a large country, it was possible to isolate the infected region and rush in resources from the rest of the country. Overall the measures used seem unlikely to be transferable to most other countries ${ }^{29}$.

South Korea instead took an approach of rapid and comprehensive testing while isolating all known cases and all their contacts $^{30}$. With no lockdown, they brought the increase off the exponential trend. That supports my opinion of how the Italian test strategy went wrong.

\section{Rapid growth}

The United States only showed signs of breaking exponential growth after over 300,000 cases were reported on 4 April 2020. Some days during March 2020, growth was at $40 \%$ or more per day with a doubling time of two days and, up to 24 March, doubling time was generally three days or less.

Over the period 2-20 March 2020, growth in the US ranged from $24 \%$ to $49 \%$ per day. With that level of growth, the United States had no option but to implement increasingly countrywide lockdowns. Other countries that resisted this strategy ran into exactly the same issue: exponential growth defeated their health systems.

In a relatively large country like the US, if growth is not even across the country, there is the option to rush resources to the hotspots as was done in China. However, this option is not as attractive as stopping the spread much earlier as the hotspots become extremely resource intensive. New York state for example has been widely reported as estimating a requirement of 40,000 ventilators at peak ${ }^{3}$ though the actual peak number of cases requiring ventilation did not come close to this level ${ }^{31}$.

Localities that have suffered this sort of resource intensity have also generally had higher case fatality rates. This could in part be an artefact of inadequate testing that under-counts cases. However Italy (13\% case fatality) has a higher per capita rate of testing than Germany (3.4\% case fatality) as of 20 April 2020: 23,985 per million population vs. 20,629 for Germany. Under-counting asymptomatic cases is not likely to be the sole issue.

\section{Other factors}

An important factor to consider is comorbidities. South Africa has high rates of tuberculosis and HIV infection, both of which are significant risk factors for any pulmonary disease ${ }^{32}$. In one study in Italy, out of 355 patients who died, only 3 $(0.8 \%)$ had no prior condition. $25.1 \%$ had one condition, $25.6 \%$ had two and $48.5 \%$ had three or more ${ }^{27}$.

Balanced against this is early statistical evidence that differences in national coverage of the Bacillus Calmette-Guerin (BCG) tuberculosis vaccine explain differences in case fatality rates ${ }^{33}$. This study is not peer reviewed and therefore should not be relied on too strongly. A pure statistical study without direct causal evidence points to the need to establish causality rather than signifying causality.

Weighed against relying on BCG coverage before further evidence emerged is that Iceland, which does not have mandatory BCG vaccination ${ }^{34}$, was very successful in slowing the spread by an aggressive testing programme, including quarantining everyone who had contacted a known case ${ }^{35}$.

More recent evidence since early versions of this paper justifies caution: there is at best mild evidence of a protective effort and no evidence that BCG slows the spread or reduces serious cases $^{36}$.

A broader lesson arises out of the early claims about BCG: a statistical study without causality could turn out to be coincidence. Another example is a study of invermectin in Peru that appears to show a close link between ivermectin use and reduced mortality ${ }^{37}$. Yet one of the first reasonably rigorous peer-reviewed studies of ivermectin shows it has no significant therapeutic effect ${ }^{38}$.

Finally there is indirect evidence of asymptomatic spread in the apparent efficacy of masks in slowing spread. While early WHO advice was against the asymptomatic mask wearing, this was part of an advisory that aimed to prevent a run on medical-grade masks ${ }^{39}$. More recently there is support for cloth masks being worn by the public ${ }^{2}$ and experimental evidence

${ }^{3}$ For example: https://abc7ny.com/ventilators-coronavirus-new-york-ny-casesin/6086097/. 
that surgical masks block aerosol transmission of coronaviruses and influenza viruses ${ }^{40}$. While some still doubt the evidence, the fact that mandatory mask wearing was a factor in reducing the spread of the 1918 influenza pandemic ${ }^{41}$ supports the case for encouraging mask-wearing as a protection for the COVID-19 pandemic provided that this does not deplete supplies of medical-grade masks and there is a programme of public education on use of masks and their role in the context of other measures like distancing and hygiene.

Given the high risk associated with comorbidities, it is premature to place too much reliance on any mitigating factors other than slowing transmission. NPIs are the main game until pharmaceutical options - including vaccines - become viable on a large scale.

\section{Proposed research}

Since earlier versions of this paper, a systematic meta-analysis and review of viral load dynamics, shedding and infectiousness has shed some light on asymptomatic transmission, indicating that asymtomatic infection is contagious but not for as long as symptomatic infection ${ }^{42}$. One study estimates the relative infectiousness of asymptomatically infected cases to be 0.27 (if on a small number of cases).

Since one of the biggest unknowns was the prevalence and contagiousness of asymptomatic infection, I proposed a project in earlier versions of this paper to identify such cases early and identify informative features. Features of interest include:

- viral shedding after initial infection; this should include variability in magnitude and duration

- prevalence in asymptomatic cases of comorbodities and risk factors like age

- testing for antibodies including those for related but more benign coronaviruses

- testing for $\mathrm{T}$ cell variability and other features of the immune system that may influence disease progression ${ }^{43}$

To identify these cases in time to measure viral shedding from the start of infection, comprehensive contact tracing of a representative sample of the infected population is necessary. Any who test positive out of this cohort can be followed up by a further round of contact tracing; if this finds more positive cases that have been in contact with only asymptomatic cases, that would provide a measure of asymptomatic contagion. If however the programme prevents secondary infections, viral shedding will still be a useful indicator of contagiousness. In one study, rapid identification and isolation of asymptomatic cases prevented secondary infections ${ }^{11}$ but this should not be taken as indicative that asymptomatic cases are not contagious.

This is a project that could be carried out with a modest burden on testing capacity - as long as the pandemic is not expanding at full pace.
Since the earlier versions of this paper, there have been some advances in understanding asymptomatic infection, including studies that show asymptomatic cases develop antibodies, if at a lower level than symptomatic cases ${ }^{44,45}$. However, given that we are no longer at the early stage of the pandemic, another related concern needs to be added to the mix: how contagious a vaccinated person could be if they are infected - despite not developing symptoms. I conjecture that this could follow the same pattern as asymptomatic infection without a vaccine: a lower rate or shorter duration of viral shedding, or both. An early study of the Pfizer-BioNTech vaccine (BNT162b2) supports this conjecture but more systematic studies over a range of vaccines will be useful to characterize the extent to which transmission is suppressed, as opposed to the primary endpoints of vaccine trials, reducing serious illness and death ${ }^{46}$. There is considerable variability in primary endpoints in vaccine trials though the public health interest focuses on severe disease so vaccine trials mostly focus on symptomatic infection with various definitions of "severe" .

The last question I raise on $\mathrm{T}$ cell variability has been addressed - even asymptomatic cases who are anti-body seronegative have a robust SARS-CoV-2-specific $\mathrm{T}$ Cell response ${ }^{48}$. This bodes well for vaccine efficacy.

\section{Conclusions}

The most significant finding out of this review is that we do not know enough about asymptomatic transmission.

This is a problem easily remedied in early-stage spread - or at a later stage when cases are reducing - and there is spare test capacity.

The proposed project would give a clearer picture of the potential for asymptomatic spread and add to the evidence for universal mask wearing.

If the experiment to measure asymptomatic spread shows that it is a significant factor, that signifies a change in testing strategy. Should any asymptomatic positives be discovered, more aggressive action should follow: they and all their contacts should be quarantined and released when they no longer test positive, taking into account time for incubation.

South Africa, at the date of the first version of the paper, had less than 3500 cases; at time of writing the second version, the daily number of cases had declined to $25 \%$ of the peak. Going back to test all contacts was doable at the outset; with test demand $25 \%$ lower than at peak, testing all contacts of a representative sample is practical. While it is possible that despite a significant asymptomatic fraction, asymptomatic infection is not contagious, the cost of finding this out is very low compared with the cost of not containing the spread. Iceland does not do widespread BCG vaccination ${ }^{34}$ and yet was successful in containing the spread. The Iceland experience indicates that there is no need to rely on questionable evidence such as that the BCG vaccine provides protection: act early and catch all cases 
including the asymptomatic and the spread can be curtailed ${ }^{35}$. However, if we know exactly how contagious aymptomatic cases are, that will further inform NPI strategy.

The cost of taking the step I advocate is far lower than the cost of allowing asymptomatic spread to get out of control. If it leads to an effective containment strategy, it will also remove the need for an economically damaging extended lockdown. Even at a later stage of the pandemic, informing policy choices like mask wearing is useful, as is better understanding of the drivers in variabililty of the disease. And economically damaging NPIs can be better avoided if we understand the disease better - how it spreads, what makes people more vulnerable.

In the time since the first draft of this paper, studies have pointed to a lower fraction of asymptomatic transmission than earlier reports but the fraction is still high enough to be a significant factor in transmission. However, I am still of the view that studying asymptomatic transmission is important as a clue to what differentiates milder cases, and could also shed light on the extent to which vaccines stop transission, as opposed to restricting infections to casuing a milder illness.

As with the early stage of the pandemic, milder to asymptomatic cases are attracting less interest in vaccine trials because they do not impose a direct public health burden. However, I argue that they impose an indirect public health burden as long as they may be contagious.

\section{Data availability}

\section{Source data}

COVID-19 data used was gathered from Worldometer: https://www.worldometers.info/coronavirus/.

Data is archived at: http://web.archive.org/web/20200422135436/ https://www.worldometers.info/coronavirus/ and the update for the second version is archived at http://web.archive. org/web/20200822095038/https://www.worldometers.info/ coronavirus/.

\section{Extended data}

The Python code used to graph herd immunity versus $R_{0}$ as well graphing doubling time and the US exponential growth scenarios is available from GitHub: https://github.com/philipmach/herd-immunity.

Zenodo: philip-mach/herd-immunity: includes herd immunity and doubling time graphs. http://doi.org/10.5281/zenodo.376235620.

Data is available under the terms of the BSD 2-clause license.
1. Feng S, Shen C, Xia N, et al.: Rational use of face masks in the CoviD-19 pandemic. Lancet Respir Med. 2020; 8(5): 434-436. PubMed Abstract | Publisher Full Text | Free Full Text

2. Greenhalgh T, Schmid MB, Czypionka T, et al.: Face masks for the public during the covid-19 crisis. BMJ. 2020; 369: m1435. PubMed Abstract | Publisher Full Text

3. Gandhi M, Yokoe DS, Havlir DV: Asymptomatic transmission, the Achilles' heel of current strategies to control COVID-19. N EnglJ Med. 2020; 382(22): 2158-2160.

PubMed Abstract | Publisher Full Text | Free Full Text

4. Tandon A, Murray CJL, Lauer JA, et al.: Measuring overall health system performance for 191 countries. Technical report, World Health Organisation, 2000.

Reference Source

5. Santacroce L, Charitos IA, Del Prete R: CovID-19 in Italy: An overview from the first case to date. Electron J Gen Med. 2020; 17(6): em235. Publisher Full Text

6. Signorelli C, Odone A, Oradini-Alacreu A, et al.: Universal Health Coverage in Italy: lights and shades of the Italian National Health Service which celebrated its 40th anniversary. Health Policy. 2020; 124(1): 69-74. PubMed Abstract | Publisher Full Text

7. Hamzelou J: World in lockdown. New Sci. 2020; 245(3275): 7 PubMed Abstract | Publisher Full Text

8. Kenyon C: Flattening-the-curve associated with reduced CoVID-19 case fatality rates- an ecological analysis of 65 countries. I Infect. 2020; 81(1): e98-e99.

PubMed Abstract | Publisher Full Text | Free Full Text

9. Hunter DJ: Covid-19 and the Stiff Upper Lip - The Pandemic Response in the United Kingdom. N Engl J Med. 2020; 382(16): e31. PubMed Abstract | Publisher Full Text

10. Gostic KM, McGough L, Baskerville EB, et al.: Practical considerations for measuring the effective reproductive number, Rt. PLoS Comput Biol. 2020; 16(12): e1008409. PubMed Abstract | Publisher Full Text | Free Full Text

11. Park SY, Kim YM, Yi S, et al.: Coronavirus Disease Outbreak in Call Center, South Korea. Emerg Infect Dis. 2020; 26(8): 1666-1670. PubMed Abstract | Publisher Full Text | Free Full Text
12. Fine P, Eames K, Heymann DL: “Herd Immunity”: a rough guide. Clin Infect Dis. 2011; 52(7): 911-916.

PubMed Abstract | Publisher Full Text

13. Coburn BJ, Wagner BG, Blower S: Modeling influenza epidemics and pandemics: insights into the future of swine flu (H1N1). BMC Med. 2009; 7(1): 30 .

PubMed Abstract | Publisher Full Text | Free Full Text

14. Fang $Y$, Nie $Y$, Penny M: Transmission dynamics of the CoviD-19 outbreak and effectiveness of government interventions: $A$ data-driven analysis. J Med Virol. 2020; 92(6): 645-659.

PubMed Abstract | Publisher Full Text | Free Full Text

15. Zhao $\mathrm{S}$, Lin $\mathrm{Q}$, Ran J, et al.: Preliminary estimation of the basic reproduction number of novel coronavirus (2019-nCoV) in China, from 2019 to 2020: A data-driven analysis in the early phase of the outbreak. Int J Infect Dis. 2020; 92: 214-217.

PubMed Abstract | Publisher Full Text | Free Full Text

16. Wu JT, Leung $K$, Leung GM: Nowcasting and forecasting the potential domestic and international spread of the 2019-nCoV outbreak originating in Wuhan, China: a modelling study. Lancet. 2020; 395(10225): 689-697. PubMed Abstract | Publisher Full Text | Free Full Text

17. Bermingham JR: Exponential population growth and doubling times: Are they dead or merely quiescent? Popul Environ. 2003; 24(4): 313-327. Publisher Full Text

18. Sibony AL: The UK COVID-19 response: A behavioural irony? Eur J Risk Regul. 2020; 1-11. Publisher Full Text

19. Gibson L, Rush D: Novel Coronavirus in Cape Town informal settlements: Feasibility of Using Informal Dwelling Outlines to Identify High Risk Areas for COVID-19 Transmission From A Social Distancing Perspective. JMIR Public Health Surveill. 2020; 6(2): e18844.

PubMed Abstract | Publisher Full Text | Free Full Text

20. Machanick P: philip-mach/herd-immunity: adds doubling time graph. 2020. http://www.doi.org/10.5281/zenodo.3762356

21. Mizumoto K, Kagaya K, Zarebski A, et al.: Estimating the asymptomatic proportion of coronavirus disease 2019 (COVID-19) cases on board the Diamond Princess cruise ship, Yokohama, Japan, 2020. Euro Surveill. 2020; 25(10): 2000180.

PubMed Abstract | Publisher Full Text | Free Full Text 
22. Day M: Covid-19: identifying and isolating asymptomatic people helped eliminate virus in Italian village. BMJ. 2020; 368: $\mathrm{m} 1165$. PubMed Abstract | Publisher Full Text

23. Byambasuren O, Cardona M, Bell K, et al.: Estimating the extent of asymptomatic COVID-19 and its potential for community transmission: systematic review and meta-analysis. J Assoc Med Microbiol Infect Dis Can. 2020; 5(4): 223-34. Publisher Full Text

24. Kronbichler A, Kresse D, Yoon S, et al.: Asymptomatic patients as a source of COVID-19 infections: A systematic review and meta-analysis. Int J Infect Dis. 2020; 98: 180-6.

PubMed Abstract | Publisher Full Text | Free Full Text

25. He J, Guo Y, Mao R, et al.: Proportion of asymptomatic coronavirus disease 2019: A systematic review and meta-analysis. J Med Virol. 2021; 93(2): 820-30.

PubMed Abstract | Publisher Full Text | Free Full Text

26. Walsh KA, Spillane $S$, Comber $L$, et al.: The duration of infectiousness of individuals infected with SARS-CoV-2. J Infect. 2020; 81(6): 847-856. PubMed Abstract | Publisher Full Text | Free Full Text

27. Onder G, Rezza G, Brusaferro S: Case-Fatality Rate and Characteristics of Patients Dying in Relation to COVID-19 in Italy. JAMA. 2020; 323(18): 1775-1776.

PubMed Abstract | Publisher Full Text

28. Summers J, Cheng HY, Lin HH, et al.: Potential lessons from the Taiwan and New Zealand health responses to the COVID-19 pandemic. The Lancet Regional Health-Western Pacific. 2020; 7(1): 100044 Publisher Full Text | Free Full Text

29. Kupferschmidt K, Cohen J: Can China's COVID-19 strategy work elsewhere? Science. 2020; 367(6482): 1061-1062.

PubMed Abstract | Publisher Full Text

30. Cohen J, Kupferschmidt K: Countries test tactics in 'war' against COVID-19. Science. 2020; 367(6484): 1287-1288. PubMed Abstract | Publisher Full Text

31. Uppal A, Silvestri DM, Siegler M, et al.: Critical Care And Emergency Department Response at the Epicenter of the COVID-19 Pandemic. Health Aff (Millwood). 2020; 39(8): 1443-1449. PubMed Abstract | Publisher Full Text

32. Boffa J, Mhlaba T, Sulis G, et al.: CoVID-19 and tuberculosis in South Africa: A dangerous combination. S Afr Med J. 2020; 110(5): 341-342. PubMed Abstract | Publisher Full Text

33. Miller A, Reandelar MJ, Fasciglione $K$, et al.: Correlation between universal BCG vaccination policy and reduced morbidity and mortality for COVID-19: an epidemiological study. medRxiv. 2020. Publisher Full Text

34. Haverkate M, D'Ancona F, Giambi C, et al.: Mandatory and recommended vaccination in the EU, Iceland and Norway: results of the VENICE 2010 survey on the ways of implementing national vaccination programmes. Euro Surveill. 2012; 17(22). pii: 20183. PubMed Abstract | Publisher Full Text

35. Stock JH, Aspelund KM, Droste M, et al.: Estimates of the undetected rate among the SARS-CoV-2 infected using testing data from Iceland. medRxiv.
2020.

Publisher Full Text

36. Escobar LE, Molina-Cruz A, Barillas-Mury C: BCG vaccine protection from severe coronavirus disease 2019 (COVID-19). Proc Natl Acad Sci U S A. 2020; 117(30): 17720-17726.

PubMed Abstract | Publisher Full Text | Free Full Text

37. Chamie-Quintero JJ, Hibberd J, Scheim D: Sharp Reductions in CoviD-19 Case Fatalities and Excess Deaths in Peru in Close Time Conjunction, State-By-State, with Ivermectin Treatments. 2021. Publisher Full Text

38. López-Medina E, López P, Hurtado IC, et al.: Effect of Ivermectin on Time to Resolution of Symptoms Among Adults With Mild COVID-19: A Randomized Clinical Trial. JAMA. 2021; e213071.

PubMed Abstract | Publisher Full Text | Free Full Text

39. World Health Organization: Rational use of personal protective equipment for coronavirus disease (COVID-19): interim guidance, 19 March 2020. Technical report, World Health Organization, 2020. Reference Source

40. Leung NHL, Chu DKW, Shiu EYC, et al.: Respiratory virus shedding in exhaled breath and efficacy of face masks. Nat Med. 2020. PubMed Abstract | Publisher Full Text

41. Cowling BJ, Aiello AE: Public health measures to slow community spread of Coronavirus Disease 2019. J Infect Dis. 2020; 221(11): 1749-1751. PubMed Abstract | Publisher Full Text | Free Full Text

42. Cevik M, Tate M, Lloyd O, et al:: SARS-CoV-2, SARS-CoV, and MERS-CoV viral load dynamics, duration of viral shedding, and infectiousness: a systematic review and meta-analysis. Lancet Microbe. 2021; 2(1): e13-e22. PubMed Abstract | Publisher Full Text | Free Full Text

43. Le Bert N, Tan AT, Kunasegaran K, et al.: SARS-CoV-2-specific T cell immunity in cases of COVID-19 and SARS, and uninfected controls. Nature. 2020; 584(7821): 457-462.

PubMed Abstract | Publisher Full Text

44. $\mathrm{Ko} \mathrm{JH}$, Joo EJ, Park SJ, et al.: Neutralizing antibody production in asymptomatic and mild COVID-19 patients, in comparison with pneumonic COVID-19 patients. J Clin Med. 2020; 9(7): 2268.

PubMed Abstract | Publisher Full Text | Free Full Text

45. Lei Q, Li Y, Hou HY, et al.: Antibody dynamics to SARS-CoV-2 in asymptomatic COVID-19 infections. Allergy. 2021; 76(2): 551-61. PubMed Abstract | Publisher Full Text | Free Full Text

46. Levine-Tiefenbrun M, Yelin I, Katz R, et al.: Initial report of decreased SARSCoV-2 viral load after inoculation with the BNT162b2 vaccine. Nat Med. 2021.

PubMed Abstract | Publisher Full Text

47. Rapaka RR, Hammershaimb EA, Neuzil KM: Are some COVID vaccines better than others? Interpreting and comparing estimates of efficacy in trials of COVID-19 vaccines. Clin Infect Dis. 2021; ciab213. PubMed Abstract | Publisher Full Text | Free Full Text

48. Sekine T, Perez-Potti A, Rivera-Ballesteros $\mathrm{O}$, et al: Robust T cell immunity in convalescent individuals with asymptomatic or mild COVID-19. Cell. 2020 183(1): 158-68.e14.

PubMed Abstract | Publisher Full Text | Free Full Text 


\section{Open Peer Review}

\section{Current Peer Review Status:}

\section{Version 3}

Reviewer Report 14 May 2021

https://doi.org/10.5256/f1000research.56040.r83832

(c) 2021 Sridhar S. This is an open access peer review report distributed under the terms of the Creative Commons Attribution License, which permits unrestricted use, distribution, and reproduction in any medium, provided the original work is properly cited.

\section{Siddharth Sridhar}

Department of Microbiology, University of Hong Kong, Hong Kong, Hong Kong

I approve the current version of the manuscript.

Competing Interests: No competing interests were disclosed.

I confirm that I have read this submission and believe that I have an appropriate level of expertise to confirm that it is of an acceptable scientific standard.

Reviewer Report 26 April 2021

https://doi.org/10.5256/f1000research.56040.r83833

(C) 2021 Mikolajczyk A. This is an open access peer review report distributed under the terms of the Creative Commons Attribution License, which permits unrestricted use, distribution, and reproduction in any medium, provided the original work is properly cited.

\section{Agata Mikolajczyk}

Department of Biochemistry and Molecular Biology, Faculty of Veterinary Medicine, Wroclaw University of Environmental and Life Sciences, Wroclaw, Poland

I have no further comments for this article.

Competing Interests: No competing interests were disclosed.

Reviewer Expertise: microbiology, molecular biology, translational medicine

I confirm that I have read this submission and believe that I have an appropriate level of expertise to confirm that it is of an acceptable scientific standard. 


\section{Version 2}

Reviewer Report 09 February 2021

\section{https://doi.org/10.5256/f1000research.29077.r77927}

(C) 2021 Mikolajczyk A. This is an open access peer review report distributed under the terms of the Creative Commons Attribution License, which permits unrestricted use, distribution, and reproduction in any medium, provided the original work is properly cited.

\section{Agata Mikolajczyk}

Department of Biochemistry and Molecular Biology, Faculty of Veterinary Medicine, Wroclaw University of Environmental and Life Sciences, Wroclaw, Poland

1. Although author of this work arise few types of COIVD-19 course among lot of variety, it gives some important general view. Nevertheless there is no type where pandemic were managed very effectively. Only there is some discussion about Iceland giving an example of extensive testing but this could be support with showing strategy of other countries which managed the best the COVID - 19 like New Zeland or Taiwan and point what was the common for this three countries.

2. Because work was writing some time ago and situation during pandemic is changing very dynamically especially in the context of vaccines, some of given strategies how to managed with current pandemic can be not timely. However it has general value as strategy for coping with any pandemic so in my opinion it is important content of this work.

3. There is lack of any detailed data which correlate wearing mask with spread of virus. There is some discussion about this and references, but here could be some investigation like: comparing spread rate of virus in countries after obligated society to wearing mask always with the one which hadn't obligate.

4. As I could see the report from second reviewer I will not double the point he has raised and I support his comments.

Is the work clearly and accurately presented and does it cite the current literature? Yes

Is the study design appropriate and is the work technically sound? Yes

\section{Are sufficient details of methods and analysis provided to allow replication by others?} Yes

If applicable, is the statistical analysis and its interpretation appropriate? Not applicable

Are all the source data underlying the results available to ensure full reproducibility? 
Yes

Are the conclusions drawn adequately supported by the results?

Partly

Competing Interests: No competing interests were disclosed.

Reviewer Expertise: microbiology, molecular biology, translational medicine

I confirm that I have read this submission and believe that I have an appropriate level of expertise to confirm that it is of an acceptable scientific standard, however I have significant reservations, as outlined above.

Author Response 09 Feb 2021

Philip Machanick, Rhodes University, Makhanda, South Africa

Thank you for your constructive comments and being willing to accept that an article that has taken a long time to get through review is worth updating for the current context.

When I first wrote it, I hoped to get it through review fast to add to the debate about asymptomatic transmission.

When I had no reviews on the first version, I updated it; doing so again, thanks to the f1000 model of keeping all version live, unintentionally turns it into a living review.

Competing Interests: No competing interests were disclosed.

Author Response 09 Apr 2021

Philip Machanick, Rhodes University, Makhanda, South Africa

1. Although author of this work arise few types of COIVD-19 course among lot of variety, it gives some important general view. Nevertheless there is no type where pandemic were managed very effectively. Only there is some discussion about Iceland giving an example of extensive testing but this could be support with showing strategy of other countries which managed the best the COVID - 19 like New Zeland or Taiwan and point what was the common for this three countries.

Thank you for raising this point. Now that we have more history, New Zealand and Taiwan present an interesting contrast in how to eliminate community spread respectively by locking down hard and early before being ready for the appopriate measures versus having the measures in place already ${ }^{1}$. I added this in to the case studies.

2. Because work was writing some time ago and situation during pandemic is changing very dynamically especially in the context of vaccines, some of given strategies how to managed with current pandemic can be not timely. However it has general value 
as strategy for coping with any pandemic so in my opinion it is important content of this work.

Thank you - I agree. As I was preparing my update, I heard the British Prime Minister, in response to a question on his biggest mistake, admitting that it was failing to consider asymptomatic transmission.

3. There is lack of any detailed data which correlate wearing mask with spread of virus. There is some discussion about this and references, but here could be some investigation like: comparing spread rate of virus in countries after obligated society to wearing mask always with the one which hadn't obligate.

Since the first reviewer pointed out that coverage of masking was inadequate I decided to remove this as a major focus. I have attempted to look into this issue but there are too many confounders to arrive at a definitive conclusion (e.g., if maskwearing reduces other NPIs in some societies, that would reduce the effectiveness of masks) $)^{2}$. In general terms the fact that asymptomatic transmission is a factor indicates that mask wearing is likely to be effective, but I have found no definitive study to back this - though e.g. the Czech experience of having one of the lowest rates of infection in Europe while masking and becoming one of the worst when masking was dropped supports the case. For this reason, I prefer to make the focus asymptomatic transmission and dropped masking as an issue.

4. As I could see the report from second reviewer I will not double the point he has raised and I support his comments.

Thank you - see my responses to the other reviewer.

\section{References}

1. Summers J, Cheng HY, Lin HH, Barnard LT, Kvalsvig A, Wilson N, Baker MG. Potential lessons from the Taiwan and New Zealand health responses to the COVID-19 pandemic. The Lancet Regional Health-Western Pacific. 2020 Oct 21:100044.

2. Cartaud A, Quesque F, Coello Y. Wearing a face mask against Covid-19 results in a reduction of social distancing. Plos one. 2020 Dec 7;15(12):e0243023.

Competing Interests: No competing interests were disclosed.

Reviewer Report 09 November 2020

https://doi.org/10.5256/f1000research.29077.r74339

(C) 2020 Sridhar S. This is an open access peer review report distributed under the terms of the Creative Commons Attribution License, which permits unrestricted use, distribution, and reproduction in any medium, provided the original work is properly cited. 


\section{Siddharth Sridhar}

Department of Microbiology, University of Hong Kong, Hong Kong, Hong Kong

This article is a description on some knowledge gaps surrounding asymptomatic COVID-19 burden. Good primer on herd immunity thresholds in the introduction. Some nice case studies. Reasonable discussion on the importance of asymptomatic/ pre-symptomatic transmission. However, there are some areas that require attention.

Overall, this manuscript reads more like a commentary/ narrative review rather than an original 'research article'.

My specific criticisms are as follows:

1. Define variables in equation 1 below the equation.

2. Apart from $R_{0}$, the concept of the effective reproduction number should also be introduced as a much more meaningful figure when NPIs are enforced.

\section{I recall closer to 700 cases on Diamond Princess. Please verify.}

4. "What is startling about these numbers is how few tested positive. Given the constrained environment of a cruise liner, a higher rate of social mixing would be expected than in normal living conditions." This is somewhat simplistic. Once the outbreak started, you would expect significant reduction in social interactions and increasing mask usage/ isolation among passengers on board the Diamond Princess, which would lower the $\mathrm{R}_{\mathrm{t}}$.

5. I do not understand how figure 2 and the equations relate to the rest of the paper. In fact, the first paragraph of the methods appears unrelated to the narrative case study/ review in the rest of the manuscript.

6. I agree with the author on the importance of detecting asymptomatic shedders, but most current estimates of true asymptomatic COVID-19 rates are less than 50\% (15-30\% according to some meta-analyses). This needs to be updated. There is also a need to differentiate between true asymptomatic infection and 'pre-symptomatic' cases who are detected before eventually going on to detect symptoms.

7. Consider citing Escobar LE et $a l^{1}$, PNAS as a peer-reviewed reference on the impact of BCG vaccination on severe COVID-19.

8. BCG vaccination is unlikely to offer sterilizing immunity against COVID-19. Instead, it is mostly being investigated for its effect on ameliorating immune responses to prevent severe COVID-19. Therefore, we can't rely on BCG vaccination to slow spread of COVID-19 and it is not a replacement for good-practice NPIs. Any country that practices high standards of NPIs, test-and-trace, and isolation-and-quarantine would be able to control COVID-19 irrespective of its BCG coverage. I feel the text is implying that BCG vaccination is under investigation for reducing COVID-19 community burden and this should be modified.

9. "Another possible mitigating factor is that existing HIV remedies are among those being investigated for efficacy against COVID-19. However, it would be foolhardy to rely on this as 
a mitigating factor without solid evidence that it applies widely enough to matter." May delete this point as lopinavir/ritonavir has been proven to be of no benefit in hospitalized COVID-19 patients in the WHO SOLIDARITY trial.

10. For the points in proposed research, several natural experiments looking at viral shedding in asymptomatic individuals (e.g. Han MS et al, Emerg Infect Dis ${ }^{2}$ ) and infectivity of asymptomatic cases (Gao $\mathrm{M}$ et al, Respir $\mathrm{Med}^{3}$ ) have already been described. Characterization of humoral and T-cell responses to COVID-19 have also been done in mild/ asymptomatic cases (Ko JH et al, J Clin $\mathrm{Med}^{4}$ ). The author may consider updating this section and reviewing the literature thoroughly to identify current research gaps.

11. The methods section in the abstract promised an examination of the strategy of using cloth face masks. However, there is no substantive discussion of cloth face masks in the text.

\section{References}

1. Escobar L, Molina-Cruz A, Barillas-Mury C: BCG vaccine protection from severe coronavirus disease 2019 (COVID-19). Proceedings of the National Academy of Sciences. 2020; 117 (30): 1772017726 Publisher Full Text

2. Han M, Seong M, Kim N, Shin S, et al.: Viral RNA Load in Mildly Symptomatic and Asymptomatic Children with COVID-19, Seoul, South Korea. Emerging Infectious Diseases. 2020; 26 (10): 2497-2499 Publisher Full Text

3. Gao M, Yang L, Chen X, Deng Y, et al.: A study on infectivity of asymptomatic SARS-CoV-2 carriers.Respir Med. 169: 106026 PubMed Abstract | Publisher Full Text

4. Ko JH, Joo EJ, Park SJ, Baek JY, et al.: Neutralizing Antibody Production in Asymptomatic and Mild COVID-19 Patients, in Comparison with Pneumonic COVID-19 Patients.J Clin Med. 2020; 9 (7).

PubMed Abstract | Publisher Full Text

Is the work clearly and accurately presented and does it cite the current literature? Partly

Is the study design appropriate and is the work technically sound? Yes

Are sufficient details of methods and analysis provided to allow replication by others? Yes

If applicable, is the statistical analysis and its interpretation appropriate? Not applicable

Are all the source data underlying the results available to ensure full reproducibility? Partly

Are the conclusions drawn adequately supported by the results? Partly

Competing Interests: No competing interests were disclosed. 
Reviewer Expertise: emerging infectious diseases, clinical virology, epidemiology/ public health

I confirm that I have read this submission and believe that I have an appropriate level of expertise to confirm that it is of an acceptable scientific standard, however I have significant reservations, as outlined above.

Author Response 09 Nov 2020

Philip Machanick, Rhodes University, Makhanda, South Africa

Thank you for constructive comments on the paper. Some of the the issues you raise are a consequence of trying to get this out quickly when this issue was fresh (version 1 was published on 4 May 2020). Unfortunately it has taken so long to find reviewers that some issues are out of date. I am happy to update the paper taking your comments into account.

The asymptomatic vs. pre-symptomatic question is a good one. Since I wrote the paper increasing evidence has been published of viral shedding prior to symptoms showing.

Your points on BCG are also good. As with several of your other points, missing some of this was a consequence of the long delay between submission and review.

I will work through the other points along with any other reviews received.

A thought experiment to clarify the role of $R_{0}$ and $R_{t}$.

$R_{0}$ depends on 3 factors (slightly simplifying Delamater et al. 2019):

1. inherent infectiousness of the pathogen

2. how long an infected person remains contagious

3. social mixing

Assume $R_{0}=2.5$ in a particular society (we must define this societally because of factor 3 assuming susceptibility is uniform).

While $R_{t}$ is a current measure as opposed to $R_{0}$, which is a base measure when everyone is susceptible, is it correct to say that NPIs change $R_{t}$ and not $R_{0}$ ?

Imagine a particularly NPI is in effect when patient zero is imported. Then $R_{0}$ will appear to be lower than without that NPI, because you have varied factor 3. However: if you wait until $40 \%$ of the population is infected and lift all NPIs, you will still expect to see herd immunity at $60 \%$ infected (based on $R_{0}=2.5$ ). So an NPI fakes the effect of a disease with lower $R_{0}$ though the measured effect is seen in $R_{t}$. Relax the NPI, and you put yourself onto a later part of the trajectory with a lower fraction susceptible than at the start, but $R_{t}$ will now climb to the point it would have been without the NPI with that fraction $(>0)$ susceptible.

So: I argue that even with NPIs in place, you really need to know $R_{0}$, because that determines the inflection point at which cases decline if you relax your NPIs even if NPIs do not actually change $\mathrm{R}_{0}$. Otherwise you get the all-too-typical active-case curve that achieves a neat peak as if you reached herd immunity then takes off again when measures relax. 
There is a lot of confusion about $R_{0}$ and $R_{t}$ so it is good to get these ideas straight. I could add this to the paper if you consider this useful; otherwise it can stay here as a comment.

\section{Reference}

Delamater PL, Street EJ, Leslie TF, Yang YT, Jacobsen KH. Complexity of the Basic Reproduction Number $\left(R_{0}\right)$. Emerg Infect Dis. 2019 Jan;25(1):1-4. doi:

10.3201/eid2501.171901. PMID: 30560777; PMCID: PMC6302597.

Competing Interests: No competing interests were disclosed.

\section{Author Response 09 Apr 2021}

Philip Machanick, Rhodes University, Makhanda, South Africa

1. Define variables in equation 1 below the equation.

Done $-E$ is the only new variable and is now explicitly rather than implicitly defined.

2. Apart from $R_{0}$, the concept of the effective reproduction number should also be introduced as a much more meaningful figure when NPIs are enforced.

Done - I explain the role of $R_{t}$ in determining progress of a pandemic and referred to it as needed.

\section{I recall closer to 700 cases on Diamond Princess. Please verify.}

The number is from the reference I cite. I checked and cannot find one that contradicts this.

4. "What is startling about these numbers is how few tested positive. Given the constrained environment of a cruise liner, a higher rate of social mixing would be expected than in normal living conditions." This is somewhat simplistic. Once the outbreak started, you would expect significant reduction in social interactions and increasing mask usage/ isolation among passengers on board the Diamond Princess, which would lower the $\mathrm{R}_{\mathrm{t}}$.

Reworded to reflect this.

5. I do not understand how figure 2 and the equations relate to the rest of the paper. In fact, the first paragraph of the methods appears unrelated to the narrative case study/ review in the rest of the manuscript.

I am trying to make the case that there is a phase of a pandemic where exponential growth will overtake health systems. Clarified.

6. I agree with the author on the importance of detecting asymptomatic shedders, but 
most current estimates of true asymptomatic COVID-19 rates are less than 50\% (15 $30 \%$ according to some meta-analyses). This needs to be updated. There is also a need to differentiate between true asymptomatic infection and 'pre-symptomatic' cases who are detected before eventually going on to detect symptoms.

I found meta-analyses supporting 15-20\%, which I think establishes your point that the fraction could be significantly lower. I added also the potential confounder of miscounting pre-symptomatic as asymptomatic.

7. Consider citing Escobar LE et $a{ }^{1}{ }^{1}$, PNAS as a peer-reviewed reference on the impact of BCG vaccination on severe COVID-19.

Done, thanks for the reference.

8. BCG vaccination is unlikely to offer sterilizing immunity against COVID-19. Instead, it is mostly being investigated for its effect on ameliorating immune responses to prevent severe COVID-19. Therefore, we can't rely on BCG vaccination to slow spread of COVID-19 and it is not a replacement for good-practice NPIs. Any country that practices high standards of NPIs, test-and-trace, and isolation-and-quarantine would be able to control COVID-19 irrespective of its BCG coverage. I feel the text is implying that BCG vaccination is under investigation for reducing COVID-19 community burden and this should be modified.

Done - and added a caution based on hindsight that correlation $\neq$ causation, with the example of a similar study of ivermectin in Peru that does not appear to be holding up.

9. "Another possible mitigating factor is that existing HIV remedies are among those being investigated for efficacy against COVID-19. However, it would be foolhardy to rely on this as a mitigating factor without solid evidence that it applies widely enough to matter." May delete this point as lopinavir/ritonavir has been proven to be of no benefit in hospitalized COVID-19 patients in the WHO SOLIDARITY trial.

A useful update - a reader who compares versions of the paper and your review will see this history so I am happy to delete this as requested. This illustrates the value of the open review model; the reader can see how our (not only - my) undestanding of the pandemic has evolved since the initial version of the paper.

10. For the points in proposed research, several natural experiments looking at viral shedding in asymptomatic individuals (e.g. Han MS et al, Emerg Infect Dis ${ }^{2}$ ) and infectivity of asymptomatic cases (Gao M et al, Respir Med $^{3}$ ) have already been described. Characterization of humoral and T-cell responses to COVID-19 have also been done in mild/ asymptomatic cases (Ko JH et al, J Clin Med ${ }^{4}$ ). The author may consider updating this section and reviewing the literature thoroughly to identify current research gaps.

Thank you for the references. I have read the Gao et al. paper and it seemed to me 
methodologically weak and this is supported by a follow-up letter by Silverman et al. ${ }^{5}$. However you make a good point that I should review progress in this regard so I have added new references to this section and added the new gap of understanding how vaccines control infectiousness. Han et al. is interesting, thanks. That led me to finding a more recent more authoritative study, Sayampanathan et al. ${ }^{6}$ I found a good reference on $\mathrm{T}$ cell response, Sekine et $\mathrm{al}^{7}$. Thanks for pointing to the need to look into this further.

11. The methods section in the abstract promised an examination of the strategy of using cloth face masks. However, there is no substantive discussion of cloth face masks in the text.

I removed this and toned down the BCG vaccine claim in the abstract. The main focus of the paper is clarified as emphasising the value of understanding asymptomatic and mild cases - even though the immediate medical emergency with a novel disease is saving the most severe cases.

\section{References}

1. Escobar L, Molina-Cruz A, Barillas-Mury C: BCG vaccine protection from severe coronavirus disease 2019 (COVID-19). Proceedings of the National Academy of Sciences. 2020; 117 (30): 17720-17726

2. Han M, Seong M, Kim N, Shin S, et al.: Viral RNA Load in Mildly Symptomatic and Asymptomatic Children with COVID-19, Seoul, South Korea. Emerging Infectious Diseases. 2020; 26 (10): 2497-2499

3. Gao M, Yang L, Chen X, Deng Y, et al.: A study on infectivity of asymptomatic SARS-CoV-2 carriers.Respir Med. 169: 106026

4. Ko JH, Joo EJ, Park SJ, Baek JY, et al.: Neutralizing Antibody Production in Asymptomatic and Mild COVID-19 Patients, in Comparison with Pneumonic COVID-19 Patients.J Clin Med. 2020; 9 (7).

5. Silverman, E. P., Reddy, R., Ataya, A., \& Eagan, C. (2020). Letter to the Editor concerning A study on infectivity of asymptomatic severe acute respiratory syndrome coronavirus 2

(SARS-CoV2) carriers by Gao et al. Respiratory Medicine, 106061. Advance online publication. https://doi.org/10.1016/j.rmed.2020.106061

6. Sayampanathan AA, Heng CS, Pin PH, Pang J, Leong TY, Lee VJ. Infectivity of asymptomatic versus symptomatic COVID-19. The Lancet. 2021 Jan 9;397(10269):93-4.

7. Sekine T, Perez-Potti A, Rivera-Ballesteros O, Strålin K, Gorin JB, Olsson A, Llewellyn-Lacey S, Kamal H, Bogdanovic G, Muschiol S, Wullimann DJ. Robust T cell immunity in convalescent individuals with asymptomatic or mild COVID-19. Cell. 2020 Oct 1;183(1):158-68.

Competing Interests: No competing interests were disclosed. 
The benefits of publishing with F1000Research:

- Your article is published within days, with no editorial bias

- You can publish traditional articles, null/negative results, case reports, data notes and more

- The peer review process is transparent and collaborative

- Your article is indexed in PubMed after passing peer review

- Dedicated customer support at every stage

For pre-submission enquiries, contact research@f1000.com 